\title{
Correlation of Meconium Stained Liquor with Cardiotocography and Its Foetal Outcome
}

\author{
Anam Khusrau Khan ${ }^{1}$, Sandhya Pralhad Pajai ${ }^{2}$ \\ ${ }^{1}$ Department of Obstetrics and Gynaecology, Datta Meghe Institute of Medial Sciences (Deemed to be \\ University), Wardha, Maharashtra, India. ${ }^{2}$ Department of Obstetrics and Gynaecology, Datta Meghe \\ Institute of Medial Sciences (Deemed to be University), Wardha, Maharashtra, India.
}

\section{ABSTRACT}

\section{BACKGROUND}

Meconium stained liquor is considered as a sign of non-reassuring foetal status and is associated with adverse foetal outcome. We wanted to evaluate the correlation of Meconium Stained Liquor (MSL) with cardiotocography (CTG) and observe the mode of delivery and foetal outcome in term pregnancy (37-42 weeks).

\section{METHODS}

This is an observational study, conducted at A.V.B.R.H., Sawangi, Meghe, Wardha from September 2017 to August 2019 (2 years) among 140 pregnant women with Meconium Stained Amniotic Fluid (MSAF) in labour after artificial or spontaneous rupture of membranes. Continuous cardiotocography was done; foetal outcome and mode of delivery were recorded.

\section{RESULTS}

The distribution of women according to grades of MSL, shows that $40.7 \%$ had grade 1 MSL, 34.3\% had grade 2 MSL, and 25\% had grade 3 MSL. The distribution of women according to CTG characteristics, shows that $43.57 \%$ had normal CTG, 49.29 $\%$ had pathologic CTG, and $7.14 \%$ had suspicious CTG. The percentage of normal CTG was maximum in grade 1 MSL $(80.70 \%)$, percentage of suspicious CTG was maximum in grade 2 MSL (10.42\%), and percentage of pathologic CTG was maximum in grade 3 MSL (88.57\%). Maximum women with grade 1 MSL had normal vaginal delivery (70.18\%), while maximum women with grade 2 (79.17\%) and grade 3 MSL (82.86\%) had caesarean section. 93 (66.43\%) neonates required only routine care at birth and $47(33.57 \%)$ neonates required NICU admission. Out of these 47 neonates who were admitted in NICU, 7 (14.89\%) neonates had birth asphyxia, 17 (36.17\%) neonates required ventilator support, 15 (31.91\%) later on developed meconium aspiration syndrome, 1 (2.13\%) neonate developed hypoxic ischemic encephalopathy (HIE), 1 (2.13\%) neonate developed neonatal sepsis, 1 $(2.13 \%)$ neonate developed pneumonia, $2(4.26 \%)$ neonates died on their day 2 of life; i.e. neonatal mortality is $1.4 \%$ out of total cases.

\section{CONCLUSIONS}

Increasing grades of meconium stained liquor was associated with cardiotocography abnormalities and with low APGAR score at 1 min and 5 min, increased need for NICU admissions, longer duration of NICU stay, and neonatal morbidity and mortality.

\section{KEY WORDS}

Meconium Stained Liquor, Cardiotocography, Foetal Outcome
Corresponding Author: Dr. Anam Khusrau Khan, Junior Resident, Dept. of Obstetrics and Gynaecology, DMIMS (DU), Wardha-442001, Maharashtra, India.

E-mail: khan.anam37@gmail.com

DOI: $10.14260 /$ jemds/2020/346

Financial or Other Competing Interests: None.

How to Cite This Article: Khan AK, Pajai SP. Correlation of meconium stained liquor with cardiotocography and its foetal outcome. J. Evolution Med. Dent. Sci. 2020;9(20): 1585-1589, DOI
Submission 13-03-2020, Peer Review 26-04-2020, Acceptance 03-05-2020, Published 18-05-2020. 


\section{BACKGROUND}

Meconium stained liquor is one of the abnormalities of amniotic fluid. Under normal circumstances, the newborn passes meconium within the first 24 to 48 hours after birth, which is a developmentally programmed event. However, some foetuses pass meconium prior to birth. Meconium staining of liquor is found in about $12-14 \%$ of all pregnancies. Studies have suggested that meconium staining of amniotic fluid may be a probable sign of impending asphyxia.(1) Which in turn can cause severe respiratory distress and meconium aspiration syndrome.

Meconium passage from the foetal gastrointestinal tract is considered to be as a response to hypoxia, vagal stimulation, normal physiological function of a mature foetus, mesenteric vasoconstriction induced gut hyper peristalsis, falling umbilical venous saturation. ${ }^{(2)}$

Before 34 weeks of gestation passage of meconium is an uncommon finding and its incidence rises gradually after 37 weeks revealing the maturation of foetal intestinal myelination and parasympathetic innervations.(3) Although intestinal meconium appears very early in gestation, Meconium Stained Amniotic Fluid (MSAF) rarely occurs before 37 weeks of gestational age. The available methods for effective intrapartum foetal surveillance are intermittent auscultation, continuous electronic foetal heart rate monitoring and invasive techniques like foetal scalp blood sampling ( $\mathrm{pH}$ and lactate).

Thick meconium alone is not related with adverse foetal outcome with poor APGAR score as compared with clear liquor. When foetal heart rate is normal in meconium stained liquor the neonatal condition is generally similar to neonates with clear liquor. Studies have suggested that in meconium stained liquor with abnormal foetal heart rate there is poor neonatal outcome. Therefore, in meconium stained liquor continuous foetal heart rate monitoring/ foetal scalp blood sampling should be done.(4)

Cardiotocography is the most widely used, non-invasive prenatal technique to monitor foetal heart rate during labour. Meconium aspiration can lead to mild respiratory distress to severe respiratory disease and rise in perinatal morbidity and mortality.

Meconium aspiration syndrome increases in presence of non-reassuring FHR. Meconium aspiration syndrome can result in neonatal death and in up to one-third of meconium aspiration cases, there are chances of developing long term respiratory compromise.(5)

Meconium stained amniotic fluid and its association with foetal compromise has been a topic of discussion(6). Hence, this observational study has been undertaken to find the correlation between meconium stained liquor with cardiotocography characteristics and foetal outcome.

\section{METHODS}

This was an observational study, conducted at A.V.B.R.H., Sawangi, Meghe, Wardha between September 2017 to August 2019 ( 2 years). Total 140 patients with meconium stained amniotic fluid during labour were studied. Institutional Ethics Committee Approval was obtained.

\section{Inclusion Criteria}

Patients who were willing to participate in the study, gestational age between 37-42 weeks, cephalic presentation, singleton pregnancy, meconium stained liquor after spontaneous rupture of membrane or artificial rupture of membrane in labouring patients.

\section{Exclusion Criteria}

Patients who were not ready to get enrolled in study, pregnant women with unknown Last Menstrual date, gestational age less than 37 weeks, previous history of caesarean section, multiple pregnancy, malpresentations, ${ }^{2}$ oligohydramnios and Intra Uterine Growth Restriction, high risk pregnancy (e.g. pre-existing maternal disease, pregnancies with hypertensive disorder, pregnancies with diabetes mellitus, complicated obstetrical history), congenital malformations in the foetus.

\section{Sample Size}

Estimated sample size for the study was 140 cases based on following formula.

\section{Sample Size Calculation}

$N=\frac{\mathrm{X}^{2} \cdot \mathrm{N} \cdot \mathrm{P}(1-\mathrm{P})}{\mathrm{C}^{2}(\mathrm{~N}-1)+\mathrm{X}^{2} \mathrm{P}(1-\mathrm{P})}$

Total patients of meconium stained in two years $=200$

$\mathrm{X} 2$ = Chi-square value for 1 degrees of freedom at some desired probability level. This is 3.84 at $5 \%$ level of significance

$\mathrm{P}=50 \%$ Proportion

$\mathrm{C}=$ Confidence interval of one choice $(95 \% \mathrm{CI})=0.05$

$N=\frac{3.84 \times 200 \times 0.5 \times 0.5}{\left(0.05^{2} \times 199\right)+3.84 \times 0.5 \times 0.5}$

$\mathrm{N}=140$.

140 term, labouring patients (37-42 weeks) gestational age with meconium stained liquor after rupture of membranes either spontaneous or artificial who fulfilled the inclusion criteria were included in the study after taking informed valid written consent. Patient's history was taken in detail, relevant clinical examination including general physical examination, per abdominal examination, per vaginal examination, and investigations including continuous CTG were recorded. After spontaneous or artificial rupture of membrane if there was meconium staining of liquor patients were included in the study and colour of liquor noted and continued with continuous cardiotocography monitoring till delivery. Conservative measures like lateral decubitus positioning of patient, intravenous fluid bolus, nasal oxygen inhalation were done. Amnioinfusion was done, $500 \mathrm{ml}$ of warm saline was infused as bolus, followed by continuous infusion of $3 \mathrm{ml} / \mathrm{min}$. . $^{7}$

The cardiotocography tracing were classified as normal, suspicious, pathological according to the NICE (National 
no requirement of intervention. Foetal condition in labour assessment is commonly done by Foetal Heart Rate (FHR) and by looking for meconium in amniotic fluid.(5) Meconium aspiration in utero can cause Meconium Aspiration Syndrome (MAS), which is a leading cause of perinatal death.(9)

CTG is the tool for monitoring foetal heart rate during labour. Cardiotocography is a monitoring tool which involves graphically recording of foetal heart activity (cardio) and its relations to uterine contractions (toco) (10). Both are recorded at the same time simultaneously and continuously through uterine quiescence and contraction. The CTG machine records FHR trace and uterine contractions against time.

\section{Correlation of Grades of MSL and CTG Characteristics}

In our study, the percentage of normal CTG was maximum in grade 1 MSL (80.70\%), percentage of suspicious CTG was maximum in grade 2 MSL (10.42\%), and percentage of pathologic CTG was maximum in grade 3 MSL (88.57\%), which is comparable to studies done by Priyadharshini $\mathrm{M}$ et al.(5) and Khillan S et al.(11) This shows that pathologic CTG patterns are more common with grade $3 \mathrm{MSL}$, while in grade 1 MSL normal CTG patterns are more common.

\section{Correlation of Grades of MSL and Mode of Delivery}

Maximum women with grade 1 MSL had normal vaginal delivery $(70.18 \%)$, while maximum women with grade 2 $(79.17 \%)$ and grade 3 MSL (82.86\%) had caesarean section. The correlation of grades of MSL and mode of delivery is found to be statistically significant as $p$ value is 0.0001 . In a study done by Priyadharshini $\mathrm{M}$ et al.(5) the caesarean section rates in grade 2 and grade 3 meconium stained liquor were $31.21 \%$ and $69.35 \%$, while percentage of normal delivery in grade 1 MSL was $53.48 \%$ respectively. Whereas, in a study done by Patel S et al.(12) it showed that the caesarean section rates in moderate and thick meconium stained liquor were $41.86 \%$ and $78.78 \%$ respectively. The findings in a study done by Khillan $S$ et al.(11) were, caesarean section rates were $45.7 \%$ in cases of grade $2 \mathrm{MSL}, 81.51 \%$ in cases of grade 3 MSL respectively. This shows that there was increase in caesarean section rate with increase in grade of MSL which is comparable with our study. In our study $59.29 \%$ patients were delivered by caesarean section. In a study done by Espinhera MC et al.(13) $62.5 \%$ were delivered by caesarean section, the findings were consistent with our study. This shows that there is increase in operative interference in meconium stained liquor.

\section{Correlation of CTG Changes with Mode of Delivery \\ In our study we found that, maximum number of patients who had pathologic CTG findings had caesarean section (97.10\%), while maximum number of patients who had normal CTG findings had normal vaginal delivery (70.49\%).The correlation of CTG changes and mode of delivery was found to be significant as the $\mathrm{p}$ value is 0.0001 . A study done by Joshi $\mathrm{H}$ et al. (14) showed that, $67 \%$ patients had normal CTG, out of them $39(58 \%)$ had normal vaginal delivery, $6(9 \%)$ had instrumental delivery and $22(33 \%)$ had caesarean section. $21 \%$ patients had suspicious CTG, out of them $9(43 \%)$ had normal vaginal delivery, 1 (5\%) had}

instrumental delivery and $11(52 \%)$ had caesarean section. $12 \%$ patients had pathologic CTG, out of them 1 (8\%) had normal vaginal delivery, $1(8 \%)$ had instrumental delivery and $10(84 \%)$ patients had caesarean section. This shows that maximum number of patients who had pathologic CTG findings had caesarean section, while maximum number of patients who had normal CTG findings had normal vaginal delivery. The findings were comparable with our study.

\section{Neonatal Outcome \\ Grades of MSL and APGAR Score at 5 min.}

Our study reveals that, $16.43 \%$ cases had APGAR score $<7$, and $83.57 \%$ had APGAR score $\geq 7$. In grade 3 MSL there were more neonates with APGAR score $<7$ at 5 min (42.86\%) as compared with grade 1 (1.75\%) and grade 2 MSL (14.58\%). The correlation of grades of MSL with APGAR score at $5 \mathrm{~min}$ is statistically significant as p value is 0.0001 . Qadir $\mathrm{S}$ et al.(4) found that $20.4 \%$ of the neonates had APGAR score $<7$ at 5 min, the $p$ value was 0.043 , which is statistically significant and comparable to our study. In a study done by Divya NV et al.(15) $7.2 \%$ neonates had APGAR score $<7$ and 93.2\% neonates had APGAR $>7$ at $5 \mathrm{~min}$, which was statistically significant and comparable to our study. The findings of study done by Jeevitha KJ et al.(16) were, amongst the meconium stained liquor group $10 \%$ of the neonates had APGAR score $<7$ at $5 \mathrm{~min}$, which was statistically insignificant. The findings of study done by Suresh GK et al.(17) were, amongst the meconium stained liquor group $6 \%$ of the neonates had APGAR score $<7$ at $5 \mathrm{~min}$.

\section{Correlation of CTG Changes with APGAR Score at 5 Min.} Our study shows that, 23 (16.43\%) neonates had APGAR <7 at 5 min. Maximum no of neonates having suspicious (30\%) and pathologic CTG (28.99\%) had APGAR score $<7$ at $5 \mathrm{~min}$ as compared with normal CTG $(0 \%)$. The correlation of CTG changes and APGAR score at $5 \mathrm{~min}$ is statistically significant as $\mathrm{p}$ value is 0.0001 . A study done by Kumar BV et al. (18) shows that, $17.2 \%$ patients who has meconium stained fluid with normal tracing had low APGAR score, while 32.8\% patients who had meconium stained fluid with abnormal tracing had low APGAR score. This shows that more no. of patients with abnormal tracings had low APGAR score as compared with normal tracing. The findings are comparable with our study.

\section{Correlation of Grades of MSL, CTG Changes with Neonatal Morbidity and Mortality amongst Neonates Admitted in NICU}

Our study shows that, 93 (66.43\%) neonates required only routine care at birth and $47(33.57 \%)$ neonates required NICU admission. Out of these 47 neonates those admitted in NICU, 7 (14.89\%) neonates had birth asphyxia, 17 (36.17\%) neonates required ventilator support, 15 (31.91\%) later on developed meconium aspiration syndrome, 1 (2.13\%) neonate developed Hypoxic Ischemic Encephalopathy (HIE), 1 (2.13\%) neonate developed neonatal sepsis, 1 (2.13\%) neonate developed pneumonia, $2(4.26 \%)$ neonates died on 
their day 2 life i.e. neonatal mortality is $1.4 \%$ out of total cases. In a study done by Patel S et al.(12) they found that 215 (86\%) neonates were asymptomatic at birth and 35 (14\%) required NICU admission. Out of these 35 neonates Admitted to NICU, 5 (14.28\%) had birth asphyxia, 17 (48.57\%) neonates required ventilator support and $14 \quad(40 \%)$ developed meconium aspiration syndrome. The above findings were similar to our study.

Neonatal morbidity i.e. birth asphyxia, meconium aspiration syndrome, requirement of ventilator support, hypoxic ischemic encephalopathy, pneumonia and neonatal sepsis was found in patients having suspicious, pathological CTG and in grade 2, grade 3 MSL. The correlation between CTG changes and neonatal complications is found to be statistically insignificant ( $p$ value 0.35 ). In our study, neonatal mortality was seen in patients having grade 3 MSL and pathologic CTG.

Neonatal mortality in our study was $1.4 \%$. Bansal S et al.(2) found the perinatal mortality rate of $1.85 \%$ in their study. The perinatal mortality rate was $0.86 \%$ in a study done by Akhila $\mathrm{S}$ et al.(19) The perinatal mortality rate was $1 \%$ in a study done by Hanoudi BM et al. (20) Neonatal mortality rate in our study is comparable to above three studies.

\section{CONCLUSIONS}

Increasing grades of meconium stained liquor were associated with cardiotocography abnormalities. Increasing grades of meconium stained liquor and cardiotocography abnormalities were associated with increased operative interference. Increasing grades of meconium stained liquor and cardiotocography abnormalities were associated with low APGAR score at $1 \mathrm{~min}$ and $5 \mathrm{~min}$, increased need for NICU admissions, longer duration of NICU stay, and neonatal morbidity and mortality.

Limitations

Small sample size and short study period.

\section{REFERENCES}

[1] Odongo BE, Ndavi PM, Gachuno OW, et al. Cardiotocography and perinatal outcome in women with and without meconium stained liquor. East African Medical Journal 2010;87(5):199-204.

[2] Bansal S, Banerjee KP, Pant R, et al. Study of foetal and neonatal outcome in meconium stained amniotic fluid in low risk parturient. Sch J App Med Sci 2017;5(3D):990-4.

[3] Mundhra R, Agarwal M. Foetal outcome in meconium stained deliveries. Journal of Clinical and Diagnostic Research 2013;7(12):2874-6.

[4] Qadir S, Jan S, Chachoo JA, et al. Perinatal and neonatal outcome in meconium stained amniotic fluid. Int J Reprod Contracept Obstet Gynecol 2016;5(5):1400-5.
[5] Priyadharshini M, Panicker S. Meconium stained liquor and its foetal outcome-retrospective study. IOSR Journal of Dental and Medical Sciences 2013;6(2):27-31.

[6] Tayade $S$. The significance of meconium stained amniotic fluid-a cross sectional study in a rural setup. Int J Biomed Adv Res 2012;3(12):861-6.

[7] Owen J, Henson BV, Hauth JC. A prospective randomized study of saline solution amnioinfusion. Am J Obstet Gynecol 1990;162(5):1146-9.

[8] NICE (National Institute for Clinical Excellence). Intrapartum care for healthy women and babies. Clinical guideline (CG 190) Published date: December 2014, last updated: February 2017.

[9] Ahanya SN, Lakshmanan J, Morgan BLG, et al. Meconium passage in utero: mechanisms, consequences and management. Obstet Gynecol Surv 2005;60(1):45-56.

[10] Aldirevie Z, Devane D, Gyte GML. Continuous cardiotocography (CTG) as a form of electronic foetal monitoring for foetal assessment during labour. Cochrane Database Syst Rev 2006;(3):CD006066.

[11] Khillan S, Dahra J, Kaur P. Adverse perinatal outcome and mode of delivery in patients with meconium stained amniotic fluid. International Journal of Clinical Obstetrics and Gynaecology 2018;2(6):22-6.

[12] Patel S, Desai B, Thanvi R. Meconium stained liquor and neonatal outcome. Papirex - International Journal of Research 2016;5(7):368-9.

[13] Espinheira MC, Grilo M, Rocha G, et al. Meconium aspiration syndrome-the experience of a tertiary center. Revista Portuguesa de Pneumologia (English Edition) 2011;17(2):71-6.

[14] Joshi H, Pawar SM, Singh A. Role of admission test by cardiotocography (CTG) as a predictor of perinatal outcome: a prospective study. International Journal of Clinical Obstetrics and Gynaecology 2019;3(2):128-31.

[15] Divya NV, VasanthaLaxmi GN. Perinatal outcome in meconium stained liquor in labour. IP International Journal of Medical Pediatrics and Oncology 2018;4(1):41-6.

[16] Jeevitha KJ, Ganapathy V, Indira N. Perinatal outcome in meconium stained amniotic fluid. International Journal of Health Sciences \& Research 2015;5(10):58-64.

[17] Suresh GK, Sarkar S. Delivery room management of infants born through thin meconium stained liquor. Indian Pediatrics 1994;31(10):1177-81.

[18] Kumar BV, Raj SV, Devi S. Abnormal foetal heart tracing patterns in patients with meconium staining of amniotic fluid and its association with perinatal outcomes. Int J Reprod Contracept Obstet Gynecol 2015;4(3):629-33.

[19] Akhila S, Koppad AM, Aundhakar CD. Study of neonatal outcome in meconium stained amniotic fluid. International Journal of Medical and Health Research 2018;4(3):134-8.

[20] Hanoudi BM, Murad AM, Ali AD. Meconium staining of amniotic fluid: a clinical study. Br Journal of Medicine and Medical Research 2014;4(3):914-21. 